\title{
Ink marks, bronze crossbows and their implications for the Qin Terracotta Army
}

CrossMark

\author{
Andrew Bevan ${ }^{1 *} \mathbb{D}$, Xiuzhen $\mathrm{Li}^{1,2}$, Zhen Zhao ${ }^{2}$, Jianhua Huang ${ }^{2}$, Stuart Laidlaw ${ }^{1}, \mathrm{Na} \mathrm{Xi}^{2}$, Yin Xia ${ }^{2}$, Shengtao Ma ${ }^{2}$ \\ and Marcos Martinon-Torres ${ }^{3}$
}

\begin{abstract}
At the heart of bureaucratic practice during Warring States and early Imperial China were regular, small acts of accountancy in which objects and people were marked so that their movements could be kept track of, their quality checked and their numbers marshalled. In the mausoleum complex of the Qin Shihuang (259-210 BC, the First Emperor of the Qin Dynasty), the longer texts and shorter inscribed marks found on the bronze weapons of the Terracotta Army are reasonably well known, and such information helps us to understand aspects of Qin craft organisation and logistics at this crucial period of Chinese state formation. This paper's modest starting point is a study of two further, less well-known ink inscriptions found on crossbow triggers from Terracotta Army Pit 1. Using multispectral photography, digital microscopy and Raman analysis, we uncover evidence of further marks on the same two triggers that suggest a similar pattern of 'matching' marks as suggested by the incised evidence. We also identify the black substance used to make the marks as a soot-based ink. Spatial analysis of both the inked and incised trigger marks then provides wider context for how such marking practices amongst Qin bronze-workers may have operated.
\end{abstract}

Keywords: Empire, Raman, Multispectral, Spatial analysis, Craft production

\section{Introduction}

The marking of names, codes, numbers or abstract symbols on artefacts is a commonplace practice in many complex societies worldwide, whether such marks are motivated by a desire for artistic accreditation, piecework payment, manufacturing quality control, military accounting or by several other possible factors [1]. Marking practices are particularly salient features of European and Asian societies during the first millennium BC, and arguably such marks both enabled and reflected increasing scales of socio-political organisation at the time, from the city-states of Hellenistic Greece, to Republican and early imperial Rome, to Warring States and early Imperial China [2, 3]. Marking practices amongst the Warring States (475-221 BC) and then the Qin Empire (221-206 $\mathrm{BC})$, are especially visible [4-10], with the testimony of contemporary Qin documents demonstrating how closely these small-scale acts of recording fitted into

\footnotetext{
${ }^{*}$ Correspondence: a.bevan@ucl.ac.uk

1 University College London, London, UK

Full list of author information is available at the end of the article
}

the wider workings of the emerging empire. The mausoleum of China's First Emperor, Qin Shihuang (259-210 $\mathrm{BC})$, provides an excellent example in this respect, and elsewhere we have summarised the many marks present on both the warriors of the well-known Terracotta Army from Pit 1 (Fig. 1), and on the weapons they carried [building on important work by 3,10 ].

This paper takes as its modest starting point, a reinvestigation of two previously identified ink marks on bronze crossbow triggers from Terracotta Army Pit 1. In contrast to incised marks which are commonplace on a variety of weapons from the mausoleum [11, 12], ink marks have only very rarely been identified so far. In total, three black-painted marks have so far been identified on the over 200 crossbow triggers recovered from Pit 1 (with the characters Jia 甲 (1st of the ten Heavenly Stems notation), $W u$ 武 (martial) and Jiu 九 (the number nine), while a red-painted mark (Sigong, 寺工, referring to the Qin central workshop) has also been found on a lance scabbard [12-14]. By applying a range of analytical techniques-multispectral photography, digital microscopy and Raman spectroscopy-we are however able both to 

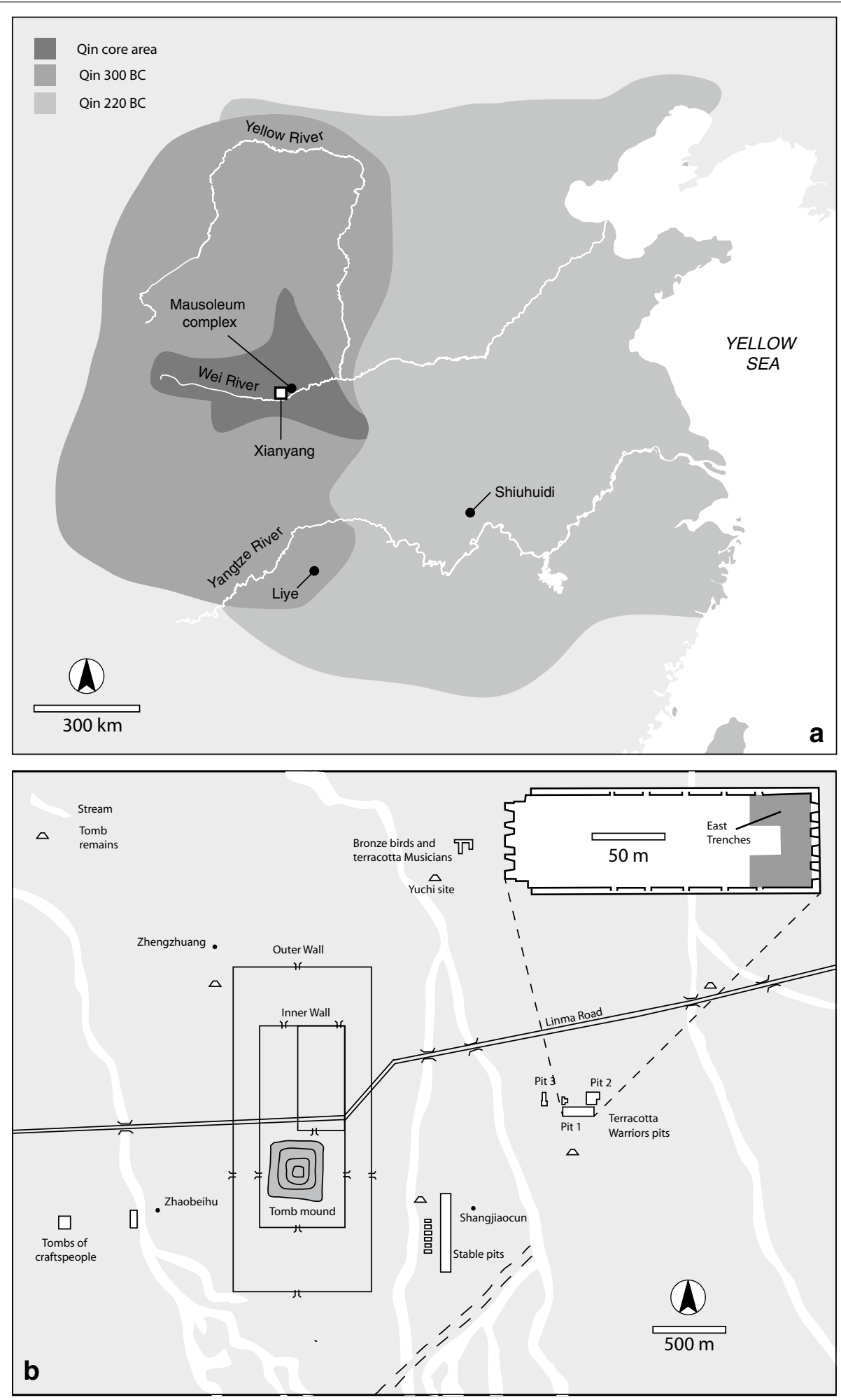

Fig. 1 a The heartland of the Qin state and a rough impression of the territorial extent of the Qin empire, with sites mentioned in the text, and $\mathbf{b}$ a plan of the mausoleum complex, with Pit 1 shown inset 
shed further light on known instances of ink marks and to identify previously unrecognised, matching marks on other parts of the same triggers and to suggest what substance was used to make the ink. Additional spatial analysis of all known marks on the crossbow triggers in Pit 1, and further attention to crossbow trigger microstyle and Qin documentary sources, extend our previous conclusions about Qin artefact marking practices, imperial workshop organisation and product quality control in this crucial period of early Chinese political consolidation. These insights also fit into a long-term programme of collaborative research on Qin imperial logistics $[11,12$, 15-20].

In what follows, we begin by discussing the use of multispectral photography and digital microscopy for better visualisation of existing marks and prospection of new ones. Then discussion moves on to consider the likely nature of the marking substance via Raman spectroscopy. Spatial analysis of the wider set of trigger marks from the easternmost trenches of Pit 1 then allows us to place these trigger marking practices in wider context, before a final section reflects on the broader implications for Qin manufacturing practices and the equipping of the first emperor's mausoleum.

\section{Methods}

Multispectral imaging is increasingly important as an approach in archaeological and heritage materials science and for object-scale assessments in related subject areas such as conservation, digital humanities and art history [21, 22]. A full imaging survey of all the bronze weapons from the Terracotta Army pits-using one or more multispectral scanners spanning the visible, nearand short-wave infrared for example-is highly desirable in future. However, for the immediate and preliminary purposes of this paper, we have explored the potential of multispectral photography for characterising existing ink marks on the weapons and potentially identifying new ones, especially with a view to cheap flexible usage in a variety of laboratory and on-site settings. To achieve this, a specially-designed camera (Fujifilm IS Pro) was used with a sensor responsive to an unusually wide UV, visible and near infrared (VNIR) range of the electromagnetic spectrum (approximately 380-1000 nm). The following workflow was used for capture and processing: (1) an ordinary RGB photograph was taken by applying a UV/IR-cut 'hot' filter to the camera; (2) IR-pass filters were used to capture four infrared images of increasing spectral range. Then (3) slight adjustment of each image for tonal range and exposure, then creation of an image stack of all acquired images. (4) Because of the different focal lengths that pertain to different infrared filters, small spatial adjustments were made to each image in the stack to ensure accurate co-registration. (5) The background of all images was masked out to ensure it played no role in subsequent multivariate image processing. (6) An orthogonal transformation (ordinary PCA) of the image stack was conducted, and (7) a false colour composite produced using the two most insightful principal components. Given the preliminary nature of the sample, we have not formalised a predictive model discriminating ink versus non-ink surfaces, and have opted for PCA as a most widely-known ordination method, rather than cross-comparing many different approaches to multivariate discrimination. We also explored the potential of UVexcited florescence (via a UV torch and lamp) to study ink marks, corrosion and other variability on the weapon surfaces, but this proved to be of marginal added value. We studied six triggers in this manner, but focused on two that were already known to have one ink mark each. As a complement to the above results from multispectral photography, and alongside closer-range digital microscopy (with a Dino-Lite USB digital microscope), Raman spectroscopy was also performed with a Renishaw inVia Raman Microscope, using a $514 \mathrm{~nm}$ Nd:YAG laser for the full spectral range from 100 to $4500 \mathrm{~cm}^{-1}$. Cosmic noise was removed, and manual baseline correction and normalisation applied. Finally, we mapped all types of crossbow marks across the easternmost trenches of Pit 1 in order to place the rare ink inscriptions in a wider context provided by the spatial distribution of incised crossbow marks that are found in larger numbers.

\section{Results}

\section{Multispectral photography and digital microscopy}

Figure 2 provides an enhanced RGB image and two IR images of a trigger with a clearly visible, previously known mark (a Chinese character, Jia 甲). However, these contrast-stretched images already suggest a possible second mark on part A (the trigger itself or handle), and the false colour composite of PCA bands from multispectral photography in Fig. 3a makes this clearer still. Figure 3b shows a false colour composite of another trigger with a previously known ink mark (the numeral 9, Jiu 九, next to a chiseled character $X u$ 戌 7th character of the twelve Earthly Branches notation), and again we were able to use the newly acquired images to identify a second 九 mark on part $C$ (the rocking lever of the trigger). A chiseled non-character symbol was found on part B (the tumbler) of the same trigger.

As a complement to the above results from multispectral photography, closer-range digital microscopy allowed us to confirm the presence of carbonaceous, black material in the locations identified as definite marks (Fig. 4a, b). The very fine-grained texture of these marks, as well as their well-defined contours, suggests that they were 


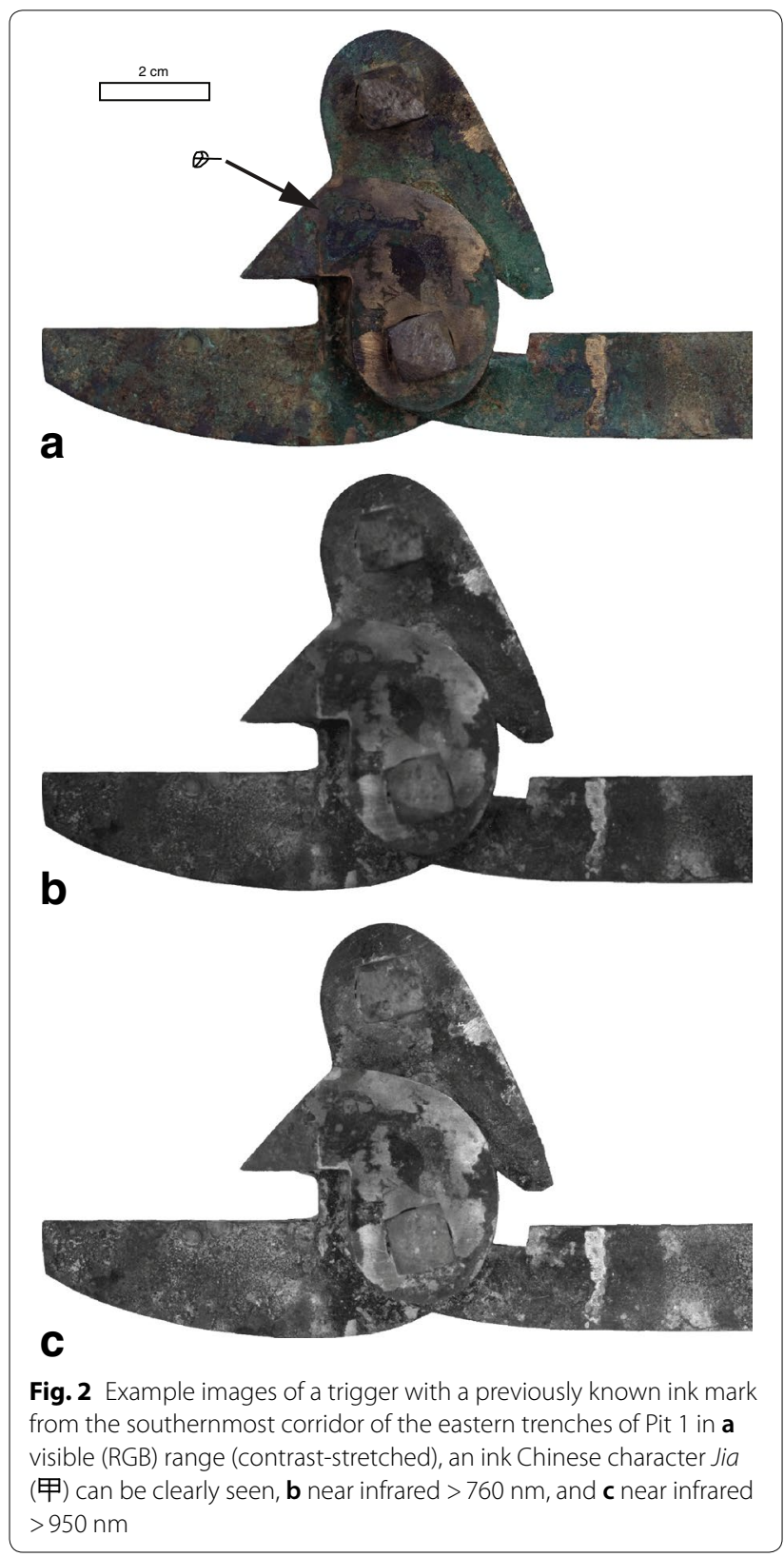

painted using liquid pigment with a brush, as opposed to, for example, drawing with a harder crayon. Further assessment via scanning electron microscope provided a clear image of brush painting with high carbon identified for the black lines of Chinese character against its bronze background.

At the same time we took the opportunity to compare examples of chiselled marks on the triggers and confirmed evidence from a previous study using SEM [11] that the incised marks were made after the trigger parts had been finished used an abrasive tool of some kind. However, the portability of digital microscopes now allows examination of a much larger number of objects quickly, for patterns in the use of instruments which might be indicative of different artisans, tools or techniques in the different stages of the production, including for example styles of chiselling (Fig. 4c, d).

\section{Raman spectroscopy}

The Raman spectroscopy results demonstrate a clear difference between ink and non-ink surfaces on the triggers (Figs. 5, 6), allowing for check of candidate ink marks observed through multispectral images. Those areas that appear red in the multispectral images shown in Fig. 3b could be confirmed as dominated by malachite $\left[\mathrm{Cu}_{2} \mathrm{CO}_{3}(\mathrm{OH})_{2}\right]$, a common corrosion product in archaeological copper alloy objects, with the strongest peaks at $152,181,272$ and $432 \mathrm{~cm}^{-1}$. Raman spectra of better preserved metal surfaces (green in multispectral image) did not show any strong bands.

Of more interest, Raman spectra obtained on the black lines and patches show two bands at $\sim 1350 \mathrm{~cm}^{-1}$ and $\sim 1600 \mathrm{~cm}^{-1}$ that correspond, respectively, to the so-called 'Deffect' or D1 band, and the 'Graphite' or $G$ band (which also includes the D2 band) of carbon black. The high signal intensity or 'plateau' between both peaks is explained by an additional Deffect or D3 band at $\sim 1500 \mathrm{~cm}^{-1}$. The relatively high $\mathrm{D} / \mathrm{G}$ intensity ratio, together with the broadening of the D and G peaks and the D3 plateau are all diagnostic of amorphous or low order carbon, while the lack of a shoulder at $1200 \mathrm{~cm}^{-1}$ (D4) indicates a relatively low organic content. No peaks were recorded at $\sim 2700 \mathrm{~cm}^{-1}$, which if present would point to the presence of charcoal or graphite [23-27]. Similarly, no bands were identified in the 2700$3000 \mathrm{~cm}^{-1}$ region, which if present would have denoted the presence of proteinaceous materials such as animal glues that could have been mixed with the pigment as a binder [28].

Altogether, these features allow the identification of the material as carbon black and, more specifically, the group of 'flame carbons/soots' that are produced in the gas phase, from incomplete combustion of hydrocarbons at relatively low temperatures [25]. Raman spectra of carbonaceous materials are highly susceptible to variation depending on Raman wavelength, orientation effects and other parameters [23-25], and thus comparisons between studies should be made with caution. Even so, it is worth noting that of the many carbon-based black pigments analysed by Coccato et al. [25], our spectra best match that of 'furnace black' $(47,250)$ which is a form of amorphous carbon obtained by condensing the smoke of a luminous flame (oil, tar, pitch, resin; see also [26]). The possibility that oil-derived soot ('lampblack ink') may have been used, as opposed to wood-derived soot ('pine ink'), should 


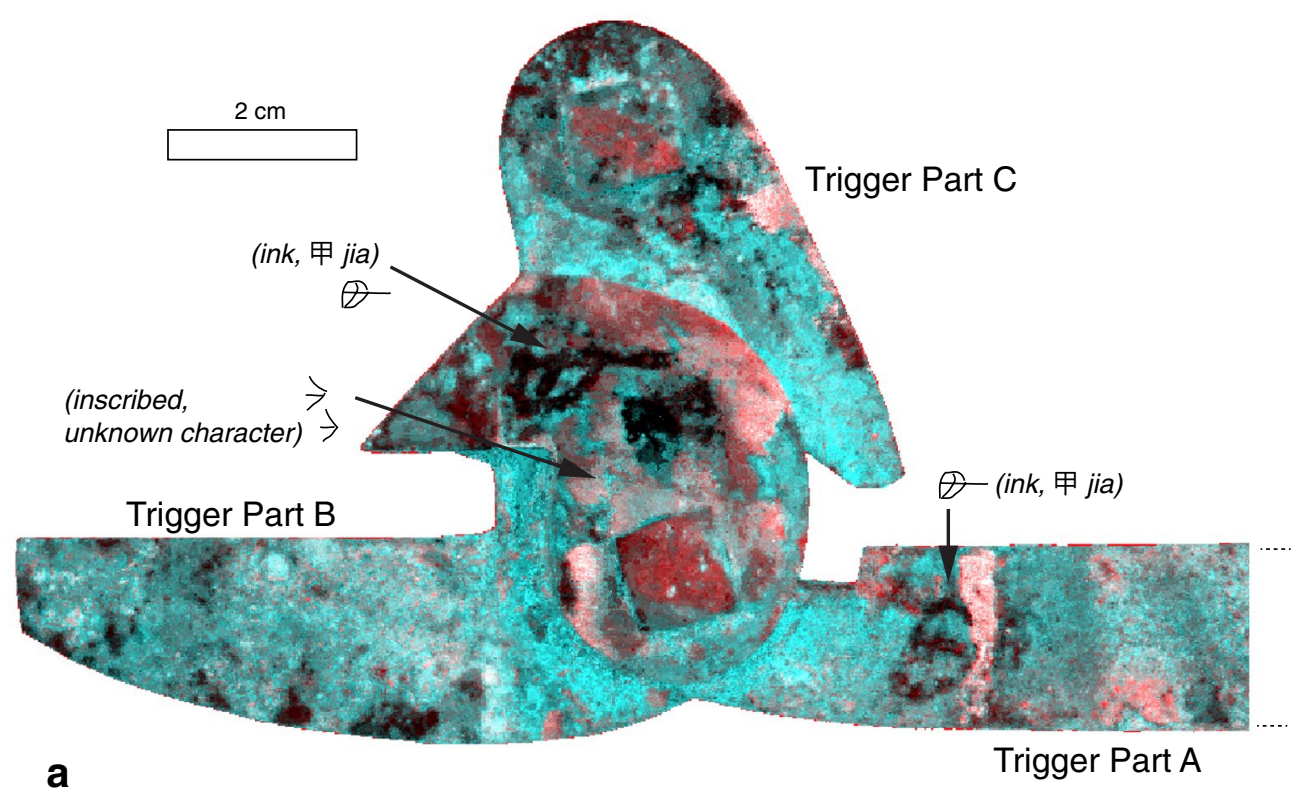

Trigger Part A
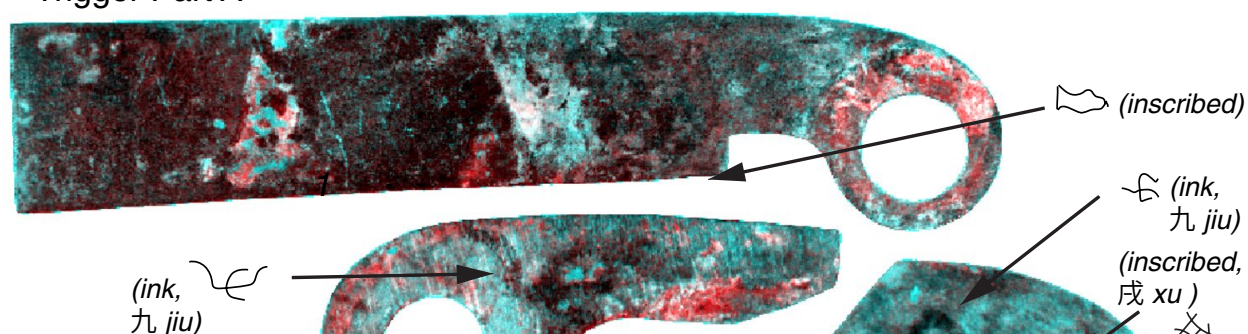
九 jiu)

Trigger Part C

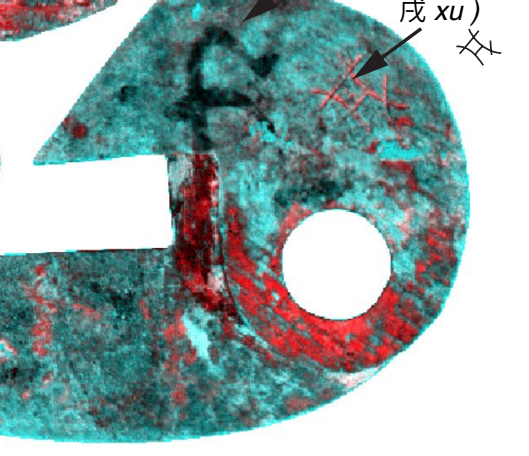

Fig. 3 Crossbows triggers shown via false colour composite images of selected PCA bands (1-7-7): a a trigger with two examples of the same Chinese character, 甲 Jia, from the southernmost corridor of the eastern trenches of Pit 1, and $\mathbf{b}$ a trigger with two examples of the numeral 9 , from the middle of the front (easternmost) corridor of Pit 1

be verified. However, the use of pine, wood-derived ink was much earlier in China from at least the Qin Dynasty (221-206 BC), while so far oil-derived, lampblack ink has only been shown to appear much later (the Southern and Northern Dynasty, AD 420-589 [26-30, 37, 38] and references therein). Moreover, it remains difficult to distinguish the two types of Chinese ink through Raman spectra, so further analyses by gas chromatography-mass spectrometry (GC-MS) would be useful to resolve this question, as well as to verify if any possible organic binder was involved [30-35].

Some individual spectra of the black pigment on the triggers include other peaks that could be identified as cuprite (Fig. 6b, strongest peak at $640 \mathrm{~cm}^{-1}$ ), quartz (Fig. 6c, strongest peaks at 464 and $209 \mathrm{~cm}^{-1}$ ) and possibly calcite (Fig. 6d, strongest peaks at 1079, 710 and 

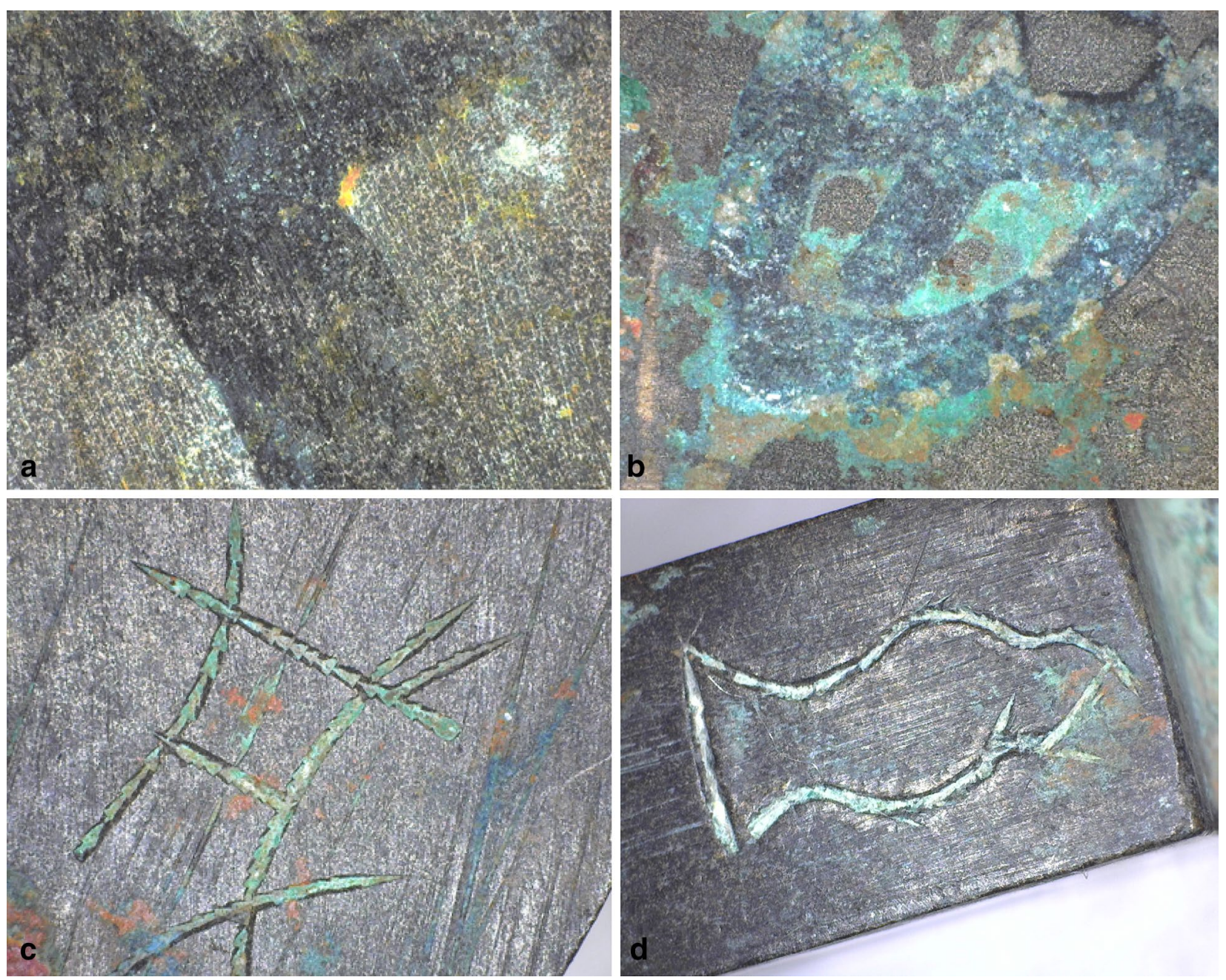

Fig. 4 Examples of some marks under the digital microscope: a the numeral 9 (九 jiu) from part A of the trigger in Fig. 3b, and small image showing the texture of brush marking; $\mathbf{b}$ part of the character (甲 jia) from part B of the trigger in Fig. 3a, $\mathbf{c}$ the incised mark from part B of the trigger in Fig. $3 \mathrm{~b}$ (戊 $x u$ ), showing very sharp chiselling with triangular tool-marks, and $\mathbf{d}$ the incised mark (a symbol or unknown character) from part A of the trigger in Fig. 3b, also showing chiselling

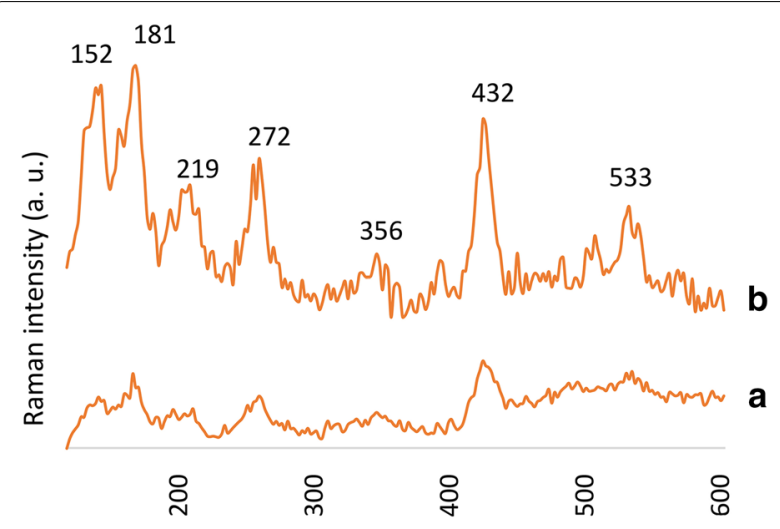

Fig. 5 Raman spectra of two spots on the trigger metal surfaces appearing green in the multispectral image in Fig. 3, showing diagnostic bands for malachite $\left.269 \mathrm{~cm}^{-1}\right)$. Supporting this identification is the fact that minuscule white or translucent minerals could be seen embedded in the black material during microscopic investigation (Fig. 4a and b). While the cuprite signal is no doubt derived from the surface patina of the underlying bronze substrate, the other minerals may result from the incorporation of soil particles on the object's surface during burial. However, an alternative possibility is that these minerals were mixed with the pigment during manufacture, or perhaps as contamination while grinding pigment pellets on an inkstone prior to use. This latter hypothesis should be investigated further through more detailed microscopic examination of both painted and control surfaces on a wider range of objects, possibly aided by experimentation. Note that 


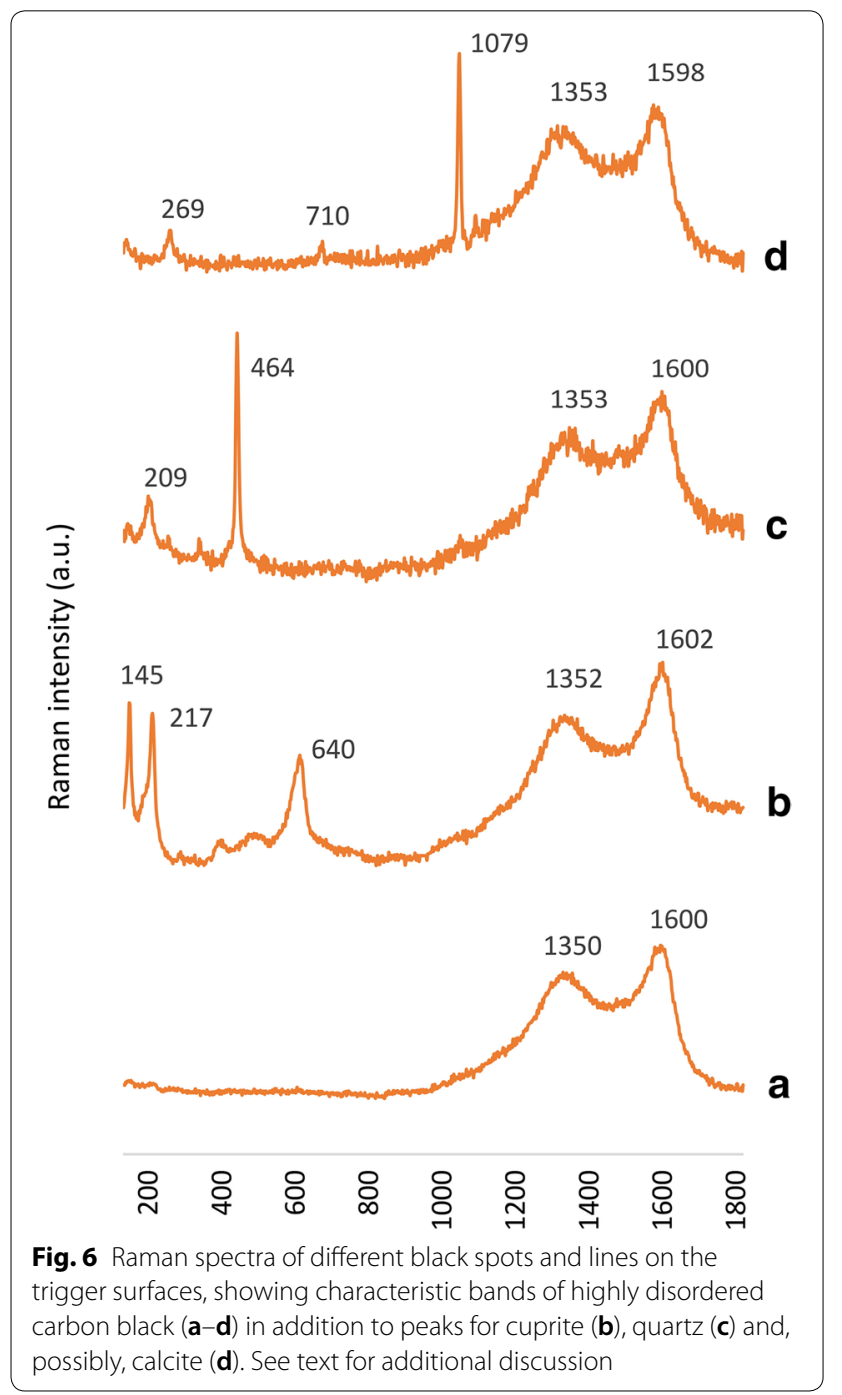

quartz was also found in one of the two samples of pigment from a Han-period inkstone analysed recently [30].

\section{Spatial analysis}

Overall, the bronze weapons from Pit 1 exhibit a large number of different kinds of incised marks. These include longer, dated texts on lances, dagger-axes and halberds, shorter inscriptions on swords and spears, and simple characters on crossbow triggers and long weapon ferrules. The crossbow was a particularly complex and important piece of Warring States and Qin period military equipment. It is therefore perhaps unsurprising that the marks on crossbow triggers are especially complex. They often appear on multiple component parts of the same trigger, with a combination of ordinary Chinese characters, numerals, 'the Heavenly-Stem and Earthly Branch notation' and further unknown symbols.
Figure 7 offers four viewpoints on these marking practices and how they are distributed across the pit. Despite the complexity of the spatial patterns at first glance, they do exhibit a certain amount of insightful structure that helps to tease out some of the patterning suggested by the matching ink marks. Figure 7a reproduces an analysis first conducted elsewhere [18] in which we made detailed measurements of different trigger parts and then used these to make groups of those examples that exhibit very similar shapes. Put simply, while it is well-known that Qin triggers from Pit 1 are highly standardised in their overall shape, the above measurements and certain typological observations nevertheless demonstrate that certain trigger shapes are more similar to each other than others. These micro-stylistic sub-groups for individual trigger parts are likely to exist because these parts were made in same or similar moulds by particular workshop cells. Similar triggers parts then stayed together when they were assembled into a whole weapon, suggesting that part manufacture was followed fairly quickly by weapon assembly, and/or that it was important to find parts that matched closely and would have operated better as an assembled mechanism. The resulting similarities continue to be visible in the pit: for example, the smaller activity areas in Fig. 7a may reflect batches of weapons from related moulds (perhaps the same workshop cell), while a preliminary interpretation of the larger identified activity areas is that they may have been parts of the pit that were equipped with weapons at the same time. Figure $7 \mathrm{a}$ also shows the location of the two analysed triggers with matching ink marks. These are both from what Li et al. [18, Table 2] referred to as Assembly Group 6 . This group is particularly interesting because (a) it is found mainly on the flanking corridors of Pit 1 ; (b) it exhibits lower overall shape variation than other groups; (c) it is frequently marked with a Gong (工, which may be an abbreviation of Sigong 寺工, and hence also referring to a central official workshop for producing metal and ceramic objects) inscription that appears to refer to a more central royal workshop (although the inked examples do not happen to have a Gong (I) reference); (d) it exhibits an unusually high propensity for multiple marks that match across parts, and (e) it demonstrates unusual consistency, for example, in exactly where on a given trigger part, the artisan made a mark (Fig. 7b-d). In other words, Assembly Group 6 exhibits more artisan care, more evidence for quality control, better final morphology and a probable link to the most important of the Qin central workshops. Given this background, it makes sense that an added bureaucratic level of ink-based marks were implemented for this group in particular.

Stepping back, it is clear that other crossbow triggers from other parts of the easternmost trench of Pit 1 (such 

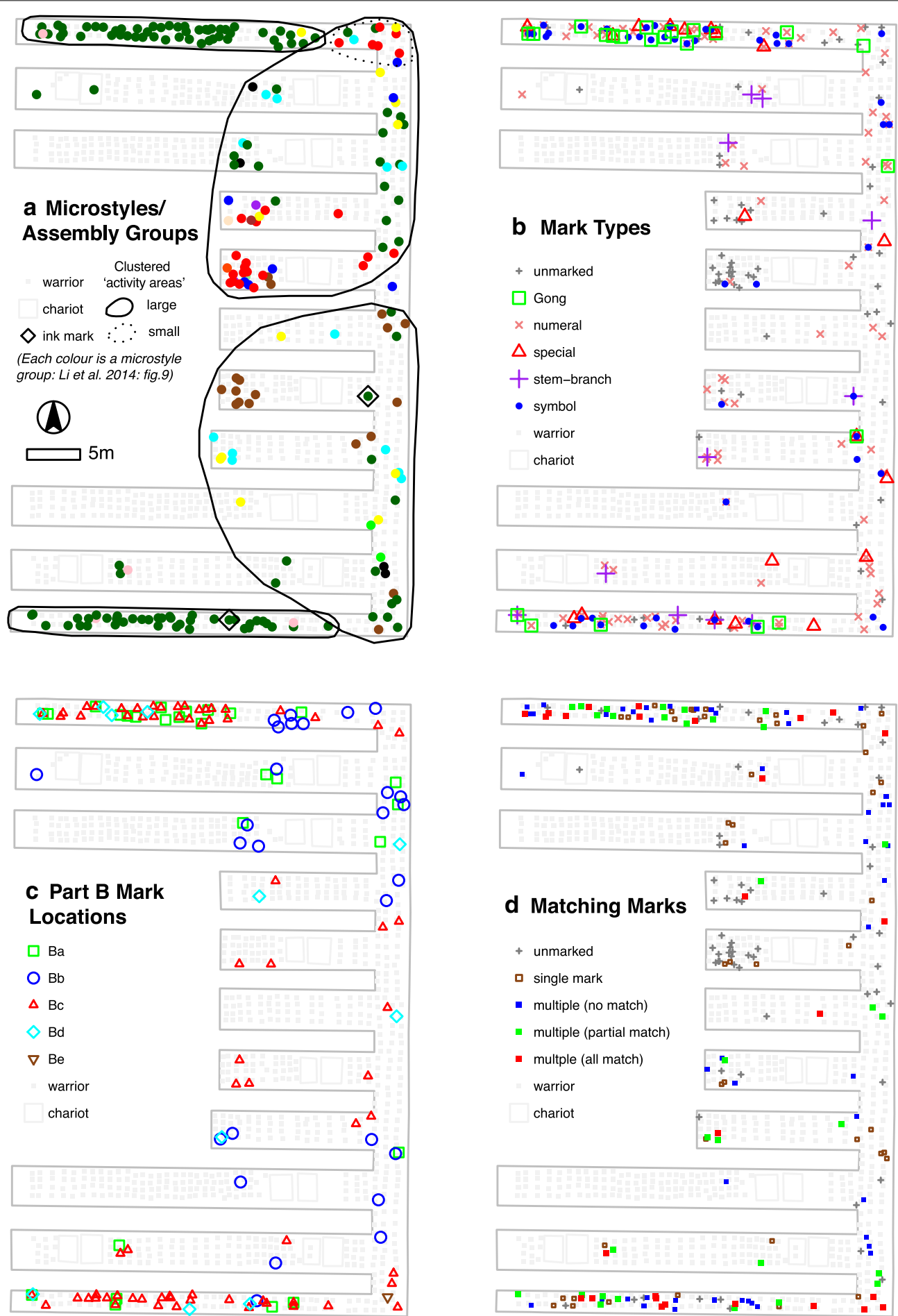

Fig. 7 Four different visualisations of the spatial distribution of triggers in the easternmost trenches of Pit 1: a trigger micro-style and assembly groups from Li et al. [18]: Fig. 9 (solid and dotted areas are marked to suggest examples of larger and smaller activity areas respectively, where trigger micro-styles are more internally consistent), $\mathbf{b}$ different types of mark, $\mathbf{c}$ different locations on part $\mathbf{b}$ where marks are found, and $\mathbf{d}$ the degree to which triggers with multiple marks exhibit matching marks 
as the front and central corridors), are more variable in shape (when looked at very closely). They also have fewer incised marks overall (and no ink marks yet) and exhibit different locations where any marks are typically placed on the trigger part (e.g. on the side, in the middle, between the two prongs part B, etc. Fig. 7c). Such greater variability may be due to a different supply chain behind how these other crossbows (rather than the more standardised Gong-related group) came to the pit. For example, perhaps they were stored for a longer time in a military arsenal (rather than coming straight from a manufacturing workshop) or perhaps they were made by different and/or less centralised workshop cells.

\section{Discussion and conclusions}

The above results provide new insights and also highlight further opportunities for analysis. First, the presence of multiple ink marks of the same character on different parts of two triggers parallels evidence from the incised marks suggesting that one of the roles of marking triggers was to ensure that accurately-fitting trigger parts could be matched up. Another role may well have been to identify the artisan(s) who made that particular trigger. However, marks identifying particular artisans are far more explicit on the terracotta warriors themselves and on long inscriptions on other kinds of weapons [12, 13] than they are on triggers. In addition, the fact that the two triggers so far identified as having ink marks, also have inscribed marks is intriguing. It suggests that perhaps the ink marks were a bureaucratic intervention that occurred later in the manufacturing and/or assembly process. In fact, the edicts preserved on bamboo slips in a tomb at Shuihudi mention the presence of painted marks on crossbows:

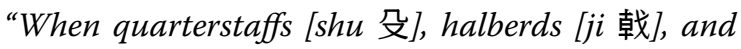 crossbows [nu 驽] (marked) in black or red (literally lacquer and cinnabar, xiutong 髹肜) have become confused (xiangyi 相易), this is not to be considered as a surplus or a shortage but is to be condemned according to Statute concerning marks not corre- sponding to the register." [5: 74; 6: B21].}

It remains unclear whether this edict is referring to crossbows that were disassembled into wooden stocks, trigger parts and other components, or is referring to whole crossbows. If the latter is the case, then the edit suggests yet an additional set of marks: those made to be seen on the outside of finished objects. In contrast the marks discussed in this paper would usually have been covered up by the wooden stock of the crossbow and usually invisible to the user, unless the crossbow was disassembled.
Also of interest are the insights provided here about marking materials, lacquer and soot-based ink. Lacquer was exploited much earlier in Chinese history than ink, for example for lacquer vessels, as an adhesive agent, for painting, and even for writing. Historical documents and archaeological evidence both indicate that ink was produced during the late Zhou Dynasty (1050$221 \mathrm{BC})$ to write on bamboo and wooden slips [33, 36, 37], such as the two fragmentary wooden slips found at Qingchuan [34]. In addition, a broken piece of soot for ink-making, $2.1 \mathrm{~cm}$ in diameter and $1.2 \mathrm{~cm}$ in height, was found in the Qin tomb of Shuihudi in $1976[4,38]$, while the tomb of Marquis Yi (ca. 475-433 BC) of the Zeng State [35] yielded earlier bamboo slips with ink characters. Given the preliminary evidence presented here for soot-based ink marking evidence on the Qin bronze triggers, an important question remains how widespread such painted/inked marking is on the wider assemblage of crossbows from Pit 1 or in other parts of the rest of the mausoleum complex. There is a much greater likelihood that such inked marks will have faded or disappeared altogether from the trigger surface, and/ or further vestiges can probably only be identified with close analytical prospection. We suggest a more comprehensive programme of study involving multispectral imaging and verification by SEM and Raman spectroscopy is worthwhile in future.

\section{Authors' contributions}

$A B, X L$ and $M M T$ designed the research described in this paper. $A B, X L, M M-T$, $Z Z, J H, S L, N X, Y X, S M$ collected the data and shared technical expertise at several stages. $A B, X L$ and $M M T$ drafted the majority of the manuscript. All authors read and approved the final manuscript.

\section{Author details \\ ${ }^{1}$ University College London, London, UK. ${ }^{2}$ Emperor Qin Shihuang's Mauso- leum Site Museum, Xi'an, China. ${ }^{3}$ University of Cambridge, Cambridge, UK.}

\section{Acknowledgements}

Xiuzhen Li's post-doctoral research is supported by Rio Tinto via the Institute for Archaeo-Metallurgical Studies (IAMS). The authors are grateful to the Emperor Qin Shihuang's Mausoleum Site Museum and the UCL Institute of Archaeology for their consistence support, as well as to the late Peter Ucko, who made the institutional collaboration possible. The Imperial Logistics project has been adopted as a flagship British Academy Research Project, and we are very grateful for this endorsement. Many thanks also to due to Thilo Rehren for his practical advice and valuable suggestions. Further thanks are due to colleagues in the Conservation and Collection departments of the Museum for their help with data collection.

\section{Competing interests}

The authors declare that they have no competing interests.

Availability of data and materials

Please contact the authors for data requests.

Funding

Beyond university and museum support, three external funding bodies kindly supported this research (the British Academy, the Institute for Archaeo-Metallurgical Studies and Rio Tinto). None of them had a role in the study design, data collection, interpretation of results or writing-up. 


\section{Publisher's Note}

Springer Nature remains neutral with regard to jurisdictional claims in published maps and institutional affiliations.

Received: 5 June 2018 Accepted: 4 December 2018

Published online: 20 December 2018

\section{References}

1. Andrássy P, Budka J, Kammerzell F, editors. Non-textual marking systems, writing and pseudo script from prehistory to modern times. Göttingen: Seminar fur Ägyptologie und Koptologie; 2009. p. 215-31.

2. Yates RDS. The Qin slips and boards from Well No. 1, Liye, Hunan: a brief introduction to the Qin Qianling county archives. Early China. 2013;35:291-329

3. Yuan Z, Liu Y. New collection and interpretation on the Qin pottery inscriptions. Beijing: Wenwu Press; 2009. (in Chinese)

4. Bianxiezu (editing group) of Yunmeng Shuihudi Qin tomb. Yunmeng Shuihudi Qin tomb. Beijing: Wenwu Press; 1981. (in Chinese)

5. Bianxiezu (editing group) of Yunmeng Shuihudi Qin tomb. The bamboo slips excavated from the Qin tomb at Shuihudi. Beijing: Wenwu Press; 2001. (in Chinese)

6. Hulsewé AFP. Remnants of Ch'in law: an annotated translation of the Ch'in legal and administrative rules of the 3 rd century BC. (Sinica Leidensia, No 17). Leiden: Brill; 1985.

7. Hunan Provincial Institute of Archaeology. Report on the excavation of Qin site at Liye. Changsha: Yuelu Publishing House; 2006. (in Chinese)

8. Hunan Provincial Institute of Archaeology. Qin bamboo slips from the site of Liye. Beijing: Wenwu Press; 2012. (in Chinese)

9. Yuan Z. Archaeological discoveries and research on the Qin terracotta warriors. Beijing: Wenwu Press; 2014. (in Chinese)

10. Li X, Bevan A, Martinón-Torres M, Xia Y, Zhao K. Marking practices and the making of the Qin Terracotta Army. J Anthropol Archaeol. 2016:42:169-83.

11. Li X, Martinón-Torres M, Meeks ND, Xia Y, Zhao K. Inscriptions, filing, grinding and polishing marks on the bronze weapons from the Qin Terracotta Army in China. J Archaeol Sci. 2011;38:492-501.

12. Li X. Standardisation, labour organisation and the bronze weapons of the Qin Terracotta warriors. Ph.D Thesis. London: University College London. 2012

13. SIAATQ (Shaanxi Institute of Archaeology and Archaeological Team of Qinshihuangling). Qinshihuang Ling Bingmayong Keng - Yihao Keng Fajue Baogao 1974-1984 [An excavation report on Pit 1 of the terracotta warriors and horses for the Emperor Qin Shihuang 1974-1984]. Beijing: Cultural Relics Press; 1988. p. 1984. (in Chinese)

14. Wang X. Monographic study on the Qin Terracotta Warriors. Xian: Sanqin Press; 1994. (in Chinese)

15. Li X, Martinón-Torres M, Meeks ND, Xia Y. Scanning electron microscopy imaging of tool marks on Qin bronze weapons using silicone rubber impressions. In: Meeks N, Cartwright C, Meek A, Mongiatti A, editors. Historical technology, materials and conservation: SEM and microanalysis. London: Archetype and The British Museum; 2012. p. 62-8.

16. Martinón-Torres M, Li X, Bevan A, Xia Y, Zhao K, Rehren Th. Making weapons for the terracotta army. Archaeol Int. 2011;13(14):65-75.

17. Bevan A, Li X, Martinón-Torres M, Green S, Xia Y, Zhao K, Cao W, Rehren Th. Computer vision, archaeological classification and China's terracotta warriors. J Archaeol Sci. 2014;49(1):249-54

18. Li X, Bevan A, Martinón-Torres M, Rehren Th, Cao W, Xia Y, Zhao K. Crossbows and imperial craft organisation: the bronze triggers of China's terracotta army. Antiquity. 2014;88:126-40.
19. Martinón-Torres M, Li X, Bevan A, Xia Y, Zhao K, Rehren Th. Forty thousand arms for a single emperor: from chemical data to labor organization in the production of bronze arrows for the terracotta army. J Archaeol Method Theory. 2014;21:534-62. https://doi.org/10.1007/s1081 6-012-9158-z.

20. Quinn PS, Zhang S, Yin X, Li X. Building the terracotta army: ceramic craft technology and production at Qin Shihuang's mausoleum complex. Antiquity. 2017;91(358):966-79.

21. Liang $\mathrm{H}$. Advances in multispectral and hyperspectral imaging for archaeology and art conservation. Appl Phys A. 2012;106(2):309-23.

22. Cosentino A. Panoramic, macro and micro multispectral imaging: an affordable system for mapping pigments on artworks. J Conserv Museum Stud. 2015. https://doi.org/10.5334/jcms.1021224.

23. Beyssac O, Goffé B, Petitet J-P, Froigneux E, Moreau M, Rouzaud J-N. On the characterization of disordered and heterogeneous carbonaceous materials by Raman spectroscopy. Spectrochim Acta A. 2003;59:2267-76.

24. Sadezky A, Muckenhuber H, Grothe H, Niessner R, Pöschl U. Raman microspectroscopy of soot and related carbonaceous materials: spectral analysis and structural information. Carbon. 2005;43:1731-42.

25. Coccato A, Jehlicka J, Moens L, Vandenabeele P. Raman spectroscopy for the investigation of carbon-based black pigments. J Raman Spectrosc. 2015:46:1003-15

26. Pawlyta M, Rouzaud J-N, Duber S. Raman microspectroscopy characterization of carbon black: spectral analysis and structural information. Carbon. 2015:84:479-90.

27. Ess MN, Ferry D, Kireeva ED, Ouf F-X, Ivleva NP. In situ Raman microspectroscopic analysis of soot samples with different organic carbon content: structural changes during heating. Carbon. 2016;105:572-85.

28. Nevin A, Osticioli I, Anglos D, Burnstock A, Cather S, Castellucci E. Raman spectra of proteinaceous materials used in paintings: a multivariate analytical approach for classification and identification. Anal Chem. 2007;79:6143-51.

29. Swider JR, Hackley VA, Winter J. Characterization of Chinese ink in size and surface. J Cult Herit. 2003;4:175-86.

30. Ren $M$, Wang $R$, Yang $Y$. Identification of the proto-inkstone by organic residue analysis: a case study from the Changle Cemetery in China. Herit Sci. 2018;6:19

31. Wei S, Fang X, Yang J, Cao X, Pintus V, Schreiner M, Song G. Identification of the materials used in an Eastern Jin Chinese ink stick. J Cult Herit. 2012;13:448-52.

32. Wei SY, Fang XY, Cao XJ, Schreiner M. Characterization of the materials used in Chinese ink sticks by pyrolysis-gas chromatography-mass spectrometry. J Anal Appl Pyrolysis. 2011;91:147-53.

33. Li J, Zhang M. Zhongguo gudai zhimoye (Ink production in ancient China). Beilin Jikan. 2001;243-52. (in Chinese)

34. Yu H. Shi Qingchuan Qinmu mudu (Interpreting Qin wooden board found in Qingchuan), vol. 1. Wenwu. 1982. pp. 22-4. (in Chinese)

35. Hubei Provicial Museum. Tomb of Marquis Yi of the Zeng State. Beijing: Wenwu Press; 1989. (in Chinese)

36. Wang L. Origin and development of ink. Forbidden City. 2014;12:70-85. (in Chinese)

37. Wang W. Zhongguo chuantong zhimo gongyi yanjiu (Researches on tradition Chinese techniques of ink stick production). Ph.D. thesis. Hefei: University of Science and Technology China. 2010. (in Chinese)

38. Chen T. The Manufacturing of pine soot ink during the Qin, Han, Wei, Jin, Northern and Southern Dynasties. Shijiazhuang University. 2013;15(1):348. (in Chinese) 